\title{
Increased Alveolar Macrophages
}

National Cancer Institute

\section{Source}

National Cancer Institute. Increased Alveolar Macrophages. NCI Thesaurus. Code C158332.

Increased number of macrophages in the terminal air spaces. 